\title{
Beneficial Effect of Bis(Hinokitiolato)Zn Complex on High-fat Diet-induced Lipid Accumulation in Mouse Liver and Kidney
}

\author{
YUKI NAITO $^{1}$, YUTAKA YOSHIKAWA ${ }^{1,2}$, KATSUHIKO YOSHIZAWA ${ }^{3}$, \\ AKIKO TAKENOUCHI ${ }^{3}$ and HIROYUKI YASUI ${ }^{1}$ \\ ${ }^{1}$ Department of Analytical and Bioinorganic Chemistry, Division of Analytical and Physical Chemistry, \\ Kyoto Pharmaceutical University, Kyoto, Japan; \\ ${ }^{2}$ Department of Health, Sports, and Nutrition, Faculty of Health and Welfare, \\ Kobe Women's University, Kobe, Japan; \\ ${ }^{3}$ Department of Food Sciences and Nutrition, School of Human Environmental Sciences, \\ Mukogawa Women's University, Nishinomiya, Japan
}

\begin{abstract}
Background/Aim: Metabolic syndrome-induced lifestyle-related diseases include diabetes mellitus (DM) and hypertension, and Zn-based compounds have effects on DM. We aimed to investigate the ameliorating effects of bis(hinokitiolato $) \mathrm{Zn},\left[\mathrm{Zn}(\mathrm{hkt})_{2}\right]$ on lipid metabolism in the liver and kidney, histopathologically. Materials and Methods: We used a high-fat diet (HFD)-fed C57BL/6J mouse model and administered a diet containing 10-20 mg $\mathrm{Zn} / \mathrm{kg}$ body weight $(\mathrm{BW})$ or $20 \mathrm{mg}$ pioglitazone $/ \mathrm{kg} B W$ as the positive control. After the treatments, we collected blood, liver, and kidney samples and morphologically evaluated the mouse organs for fat accumulation. Results: After a 4-month HFD administration, ectopic fat deposition was detected in the liver and kidney. Furthermore, Zn accumulation in the liver and kidney increased following [Zn(hkt $)_{2}$ ] treatment, that reduced lipid accumulations and lipid toxicity in these tissues. Conclusion: The results of this study suggest that [Zn(hkt $)_{2}$ ] could be a novel anti-dyslipidaemia compound for treating diet-induced obesity.
\end{abstract}

The westernization of eating habits has increased the intake of fat. Metabolic syndrome, which is caused by these changing dietary habits, induces diabetes mellitus (DM) or hypertension

This article is freely accessible online.

Correspondence to: Hiroyuki Yasui, Department of Analytical and Bioinorganic Chemistry, Division of Analytical and Physical Chemistry, Kyoto Pharmaceutical University, 5 Nakauchi-cho, Misasagi, Yamashina-ku, Kyoto, 607-8414, Japan. Tel: +81 755954629, Fax: +81 755954753, e-mail: yasui@mb.kyoto-phu.ac.jp

Key Words: Zn complex, morphological analysis, ectopic fat deposition, animal model.
$(1,2)$. There are numerous reports on the effects of a high-fat diet (HFD) intake on health, and the most serious and important are dyslipidaemia, which is characterised by hypertriglyceridaemia, hypercholesterolaemia, and fatty liver $(3,4)$.

Numerous researchers have reported the effects of many organic or inorganic compounds on various organs, leading to disorders such as fatty liver or diabetic nephropathy (5, $6)$. Furthermore, other studies have reported that some compounds, even known as beneficial food materials, can worsen a disease condition $(7,8)$. These reports suggest that careful considerations are required to understand the correct use of these food materials and evaluate their effects on both biochemical parameters and organ morphology. In particular, dyslipidaemia, which is a risk factor for cardiovascular disease, should be prevented.

Pioglitazone is known to exhibit efficacy in the treatment of DM owing to its blood glucose lowering, glycated haemoglobin (HbA1c) improvement, and glucose tolerance ameliorating effects $(9,10)$. Furthermore, numerous researchers have reported the anti-DM effect of $\mathrm{Zn}$ in in vivo experiments (11-13). For example, $\mathrm{Zn}$ compound 1) increased Akt-phosphorylation, as well as inhibited tyrosine-protein phosphatase non-receptor type 1B (PTP1B) and phosphatase and tensin homolog (PTEN) in 3T3-L1 adipocytes; and 2) inhibited alpha-glucosidase and 3) activated phosphodiesterase (14-18). Furthermore, only a few studies such as that of Moroki et al. (19) have reported experiments showing the effects of $\mathrm{Zn}$ complexes on lipid metabolism. Thus, the effects of $\mathrm{Zn}$ compounds on lipid metabolism have not been sufficiently examined yet.

The experimental animals were fed an HFD or highfructose diet to establish the metabolic syndrome or DM model $(20,21)$. Therefore, this study examined the histopathology of the livers and kidneys of C57BL/6J mice 
Table I. Composition of experimental diet.

\begin{tabular}{|c|c|c|c|c|c|}
\hline & \multirow[t]{2}{*}{$\mathrm{CNT}$} & \multirow[t]{2}{*}{ Pioglitazone } & \multicolumn{3}{|c|}{$\left[\mathrm{Zn}(\mathrm{hkt})_{2}\right]$} \\
\hline & & & $10 \mathrm{mg} \mathrm{Zn}$ & $15 \mathrm{mg} \mathrm{Zn}$ & $20 \mathrm{mg} \mathrm{Zn}$ \\
\hline Casein & 18.2 & 18.2 & 18.2 & 18.2 & 18.2 \\
\hline Sucrose & 30.0 & 30.0 & 30.0 & 30.0 & 30.0 \\
\hline Lard & 18.2 & 18.2 & 18.2 & 18.2 & 18.2 \\
\hline Vitamin mix. AIN 93N & 0.9 & 0.9 & 0.9 & 0.9 & 0.9 \\
\hline Mineral mix. AIN 93N & 3.2 & 3.2 & 3.2 & 3.2 & 3.2 \\
\hline Cellulose & 4.5 & 4.5 & 4.5 & 4.5 & 4.5 \\
\hline L-Cystine & 0.2 & 0.2 & 0.2 & 0.2 & 0.2 \\
\hline Choline bitartrate & 0.2 & 0.2 & 0.2 & 0.2 & 0.2 \\
\hline t-Butylhydroquinone & 0.0007 & 0.0007 & 0.0007 & 0.0007 & 0.0007 \\
\hline Cornstarch & 15.5 & 15.5 & 15.5 & 15.4 & 15.3 \\
\hline Sample & 0.00 & 0.02 & 0.04 & 0.08 & 0.19 \\
\hline Water & 9.1 & 9.1 & 9.1 & 9.1 & 9.1 \\
\hline Total (\%) & 100 & 100 & 100 & 100 & 100 \\
\hline
\end{tabular}

CNT: Control; $\left[\mathrm{Zn}(\mathrm{hkt})_{2}\right]$ : bis(hinokitiolato)Zn complex.

fed an HFD to determine the effects of long-term ingestion of bis(hinokitiolato) $\mathrm{Zn}$ complex, $\left[\mathrm{Zn}(\mathrm{hkt})_{2}\right]$ on lipid accumulation. Furthermore, we used pioglitazone treatment as a positive control.

\section{Materials and Methods}

Chemicals. Pioglitazone was obtained from Tokyo Chemical Ind., Co., Ltd. (Tokyo, Japan). Hinokitiol and all other chemical reagents were purchased from Wako Pure Chemical Ind., Ltd., (Osaka, Japan).

Preparation and characterisation of $\left[\mathrm{Zn}(h k t)_{2}\right]$. The $\left[\mathrm{Zn}(\mathrm{hkt})_{2}\right]$ complex was prepared in deionised water/ethanol by mixing $\mathrm{Zn}\left(\mathrm{CH}_{3} \mathrm{COO}\right)_{2}$ and hinokitiol at a 1:2 molar ratio and the solution was stirred for $12 \mathrm{~h}$ at $25^{\circ} \mathrm{C}$ room temperature. The resulting paleyellow precipitate was collected by vacuum filtration, washed several times with pure ethanol, and dried overnight in vacuo (22). These prepared complexes were characterised using elemental analysis, infrared (IR) absorption (Shimadzu FT-IR 8100A on $\mathrm{KBr}$ pellet, SHIMADZU Co., Kyoto, Japan), and low-resolution mass spectrometry (MS, JEOL JMS-SX 102AQQ, JEOL Ltd., Tokyo, Japan). The elemental analyses were performed at the Analytical Center of Kyoto Pharmaceutical University (KPU). The lowresolution mass spectra were recorded in the positive electron ionisation $[\mathrm{EI}(+)]$ mode at the Analytical Center of KPU. The elemental analysis results are as follows: (found/calcd); C 59.40/ $59.14 \%$, H 5.91/5.86\%. IR spectra (complex/ligand); $v_{\mathrm{C}=\mathrm{O}}=1591$ $\mathrm{cm}^{-1} / 1609 \mathrm{~cm}^{-1}$. EI(+) MS m/z; $390[\mathrm{M}]^{+}$.

Animals. Male C57BL/6J mice (4-week-old) were purchased from CLEA Japan, Inc., (Tokyo, Japan) and were maintained on a 12-h light/dark cycle in our central animal facility. They were housed in an air-conditioned room at a temperature and humidity of $23 \pm 1^{\circ} \mathrm{C}$
Table II. Changes in body weight (BW) and blood glucose levels (BGL) before and after a 4-month ingestion in C57BL/6J mice.

\begin{tabular}{|c|c|c|c|c|}
\hline & \multicolumn{2}{|c|}{ Body weight (g) } & \multicolumn{2}{|c|}{ BGL (mg/dL) } \\
\hline & Before & After & Before & After \\
\hline \multicolumn{5}{|l|}{ C57BL/6J } \\
\hline CNT & $20.1 \pm 0.9$ & $37.5 \pm 3.4$ & $101 \pm 33$ & $160 \pm 27$ \\
\hline Pioglitazone & $19.0 \pm 1.2$ & $38.3 \pm 3.4$ & $101 \pm 43$ & $142 \pm 23$ \\
\hline$\left[\mathrm{Zn}(\mathrm{hkt})_{2}\right]$ & $19.2 \pm 0.8$ & $30.0 \pm 4.4 * *$ & $146 \pm 31$ & $125 \pm 6 *$ \\
\hline
\end{tabular}

and $60 \pm 10 \%$, respectively. All animals were allowed free access to the standard food (Table I) and tap water. All animal experimental protocols were approved by the Experimental Animal Research Committee of KPU and were performed according to the Guidelines for Animal Experimentation of KPU.

Dietary formulations with pioglitazone and $\left[\mathrm{Zn}(h k t)_{2}\right]$. All animals had free access to water and semi-synthetic HFDs that were high in sugar and, therefore, hypercaloric (composition of the basal diet [\%]: sucrose, 30\%; lard fat, $18.2 \%$; and casein, 18.2\%; Kobe Women's University special diets, Kobe, Japan). The diets were prepared for all groups using AIN-93N and a mixture of a standard diet (Oriental East Co., Ltd., Tokyo, Japan) as shown in Table I. The dose of pioglitazone was determined based on that used in previous studies (23-25), and we prepared an HFD containing $20 \mathrm{mg} / \mathrm{kg} \mathrm{BW}$ pioglitazone for the drug treated group. Previous reports showed that the effective dose of $\mathrm{Zn}$ complexes for anti-DM activity is approximately $15 \mathrm{mg} \mathrm{Zn/kg} \mathrm{BW.} \mathrm{Furthermore,} \mathrm{we} \mathrm{prepared} \mathrm{an} \mathrm{HFD}$ 
Naito et al: Morphological Analysis of C57BL/6J with Zn Complex

Table III. Serum parameters of control (CNT), pioglitazone-, and bis(hinokitiolato)Zn complex ([Zn(hkt) 2$]$ )-treated C57BL/6J mice.

\begin{tabular}{|c|c|c|c|c|c|c|c|c|}
\hline & TG & TCHO & HDL & BUN & GPT/ALT & GOT/AST & Liver weight & Kidney weight \\
\hline & \multicolumn{4}{|c|}{$(\mathrm{mg} / \mathrm{dL})$} & \multicolumn{2}{|c|}{$(\mathrm{U} / \mathrm{L})$} & \multicolumn{2}{|c|}{ ( $\mathrm{g}$ of wet weight) } \\
\hline \multicolumn{9}{|l|}{ C57BL/6J } \\
\hline CNT & $108 \pm 20$ & $135 \pm 35$ & $114 \pm 5$ & $21.2 \pm 1.7$ & $16 \pm 5$ & $43 \pm 5$ & $1.2 \pm 0.1$ & $0.37 \pm 0.05$ \\
\hline Pioglitazone & $108 \pm 13$ & $141 \pm 12$ & $102 \pm 6^{*}$ & $17.1 \pm 0.1 * *$ & $43 \pm 17 * *$ & $55 \pm 8^{* *}$ & $1.3 \pm 0.2$ & $0.30 \pm 0.02$ \\
\hline$\left[\mathrm{Zn}(\mathrm{hkt})_{2}\right]$ & $75 \pm 19 * *$ & $122 \pm 25$ & $96 \pm 10 * *$ & $17.7 \pm 2.4^{* *}$ & $14 \pm 6$ & $41 \pm 6$ & $0.9 \pm 0.1$ & $0.30 \pm 0.03$ \\
\hline
\end{tabular}

${ }^{*} p<0.05$ and ${ }^{* *} p<0.01 v s$. CNT (control); TG: triglyceride; TCHO: total cholesterol; HDL: high-density lipoprotein; BUN: blood urea nitrogen; GPT/ALT: glutamic pyruvic transaminase/alanine aminotransferase; GOT/ALT: glutamic oxaloacetic transaminase/aspartate aminotransferase.

containing $10-20 \mathrm{mg} / \mathrm{kg} \mathrm{BW}\left[\mathrm{Zn}(\mathrm{hkt})_{2}\right]$ for the $\left[\mathrm{Zn}(\mathrm{hkt})_{2}\right]$-treated group $(26,27)$.

Animal experiments. All animals used for the in vivo study were 6-weeks-old. We purchased $20 \mathrm{C} 57 \mathrm{BL} / 6 \mathrm{~J}$ mice, which were adapted to the environment. Then, the mice were divided into three groups fed either a basal HFD (CNT) or a basal HFD containing pioglitazone or supplemented with $\left[\mathrm{Zn}(\mathrm{hkt})_{2}\right]$. The C57BL/6J mice were allowed free access to a solid HFD for the CNT group, and an HFD with pioglitazone or $\left[\mathrm{Zn}(\mathrm{hkt})_{2}\right]$ for the drug-treated groups, and tap water for 4 months. Blood glucose levels (BGL) were measured once weekly, and the $\mathrm{BW}$, food intake, and water consumption were monitored every 3 days. Blood samples for the analysis of BGL were obtained from the tail vein of the normal $\mathrm{C} 57 \mathrm{BL} / 6 \mathrm{~J}$ mice and measured using the glucose oxidase method (Glucocard, Arkray, Kyoto, Japan). In the histopathological experiments, we randomly chose three mice from each group.

Tissue fixation and processing. At 4 months of age, the liver and kidney tissues from the C57BL/6J mice were removed, fixed in $10 \%$ buffered formalin, embedded in paraffin, sectioned at $3-\mu \mathrm{m}$ thickness, and stained with haematoxylin and eosin (H\&E). The weights of the liver and kidneys were also measured.

Morphometric analysis of liver and kidney. H\&E-stained sections of each tissue were scanned using a high-resolution digital slide scanner (NanoZoomer 2.2 Digital Pathology, Hamamatsu Photonics, Hamamatsu, Japan) to prepare digital images. The ndpi image files were opened in the colour mode using the NDP.view2 software (Hamamatsu Photonics, Hamamatsu, Japan). The glomerular area was measured in the $H \& E$ sections, and average values were calculated. Histopathological and morphometric evaluations were conducted and reviewed by a toxicological pathologist (K.Y.) certificated by the International Academy of Toxicologic Pathology. The severity of the lesions was graded using the following fourpoint scale: + (minimal $),++($ mild $),+++($ moderate $)$, and ++++ (marked). To enable the comparisons of the severity of hepatocellular fatty changes, the histopathological changes were graded subjectively based on the relative width of the hepatic cords as follows:,,++++++ , and ++++ (approximately 25, 50, 75, and $100 \%$ increase in hepatic cord width, respectively. The fatty changes in the proximal tubular epithelial were graded subjectively based on the number of tubules as follows: $+(0-25 \%),++(25-50 \%) ;+++$ (50-75\%); and ++++ (75 to $100 \%)$.
Blood biochemical analysis. At euthanasia, blood samples were withdrawn from the abdominal inferior vena cava of mice exsanguinated under anaesthesia with ether, and centrifuged for 10 min at $650 \times g$ at $4^{\circ} \mathrm{C}$. The obtained serum samples were analysed to detect the concentration of blood urea nitrogen (BUN), glutamic pyruvic transaminase/alanine aminotransferase (GPT/ALT), glutamic oxaloacetic transaminase/aspartate aminotransferase (GOT/AST), triglyceride (TG), total cholesterol (TCHO), and highdensity lipoprotein (HDL) using Fuji DRI-CHEM 4000sV (FUJI FILM Medical Co. Ltd., Tokyo, Japan). GPT/ALT and GOT/AST levels reflect hepatocyte damage and, therefore, they are valuable biomarkers of chemical-induced hepatotoxicity. TG and TCHO indicate the rate of cholesterol metabolism and TG, TCHO, and HDL were used as valuable biomarkers for lipid metabolism.

Zn concentrations in liver and kidney. Liver and kidney samples were collected from all three groups, and the $\mathrm{Zn}$ levels were determined using inductively coupled plasma (ICP)-MS (Agilent 7700x/Mass Hunter; Agilent Technologies, Inc., Santa Clara, CA, USA). To determine the total amount of $\mathrm{Zn}$ in the liver and kidney, the collected samples were washed with saline and approximately $30 \mathrm{mg}$ of vacuum-dried tissue was obtained, heated to $180^{\circ} \mathrm{C}$, and $2 \mathrm{~mL}$ each of $60 \%$ nitric acid $\left(\mathrm{HNO}_{3}\right), 60 \%$ perchloric acid $\left(\mathrm{HClO}_{4}\right)$, and $30 \%$ hydrogen peroxide $\left(\mathrm{H}_{2} \mathrm{O}_{2}\right)$ was added. This procedure was repeated until all the organic material was removed. After cooling the samples to room temperature, the residues were re-suspended in $9 \mathrm{~mL} 5 \% \mathrm{HNO}_{3}$. These solutions were used for the quantitation assay for determining the $\mathrm{Zn}$ concentrations using ICP-MS.

Statistical analysis. All discrete values except for the histopathological results were expressed as the means \pm standard deviation (SD) and analysed using a one-way analysis of variance (ANOVA) and Dunnet's multiple comparison tests. Differences were considered significant at $p<0.05$ or $p<0.01$.

\section{Results}

General remarks. There were no significant differences in the BW on day 1 between the groups. At 4 months after sample treatment, the $\mathrm{BW}$ of the $\left[\mathrm{Zn}(\mathrm{hkt})_{2}\right]$ group significantly decreased compared with that of the CNT group $(p<0.01)$. 
in vivo $31: 1145-1151(2017)$

Table IV. Morphological changes in liver and kidneys after 4-month high-fat diet (HFD) ingestions.

\begin{tabular}{lccc}
\hline Group & Treatment & $\begin{array}{c}\text { Liver } \\
\text { Hepatocellular, fatty change }\end{array}$ & $\begin{array}{c}\text { Kidney } \\
\text { Tubular, fatty change }\end{array}$ \\
\hline C57BL/6J_CNT1 & HFD & + (Perilobular) & ++ \\
C57BL/6J_CNT2 & HFD & $+++($ Centrilolular) & ++ \\
C57BL/6J_CNT3 & HFD & $+++($ Centrilolular) & ++ \\
C57BL/6J_PIO1 & HFD + pioglitazone & ++ Centrilobular) & - \\
C57BL/6J_PIO2 & HFD + pioglitazone & +++ (Centrilolular) & + \\
C57BL/6J_PIO3 & HFD + pioglitazone & + (Perilobular) & - \\
C57BL/6J_Zn1 & HFD + [Zn(hkt $\left.)_{2}\right]$ & - & - \\
C57BL/6J_Zn2 & HFD + [Zn(hkt) $\left.{ }_{2}\right]$ & - & - \\
C57BL/6J_Zn3 & HFD + [Zn(hkt $\left.)_{2}\right]$ & & - \\
\hline
\end{tabular}

$\left[\mathrm{Zn}(\mathrm{hkt})_{2}\right]$ : bis(hinokitiolato)Zn complex.

Blood biochemical analysis. The $\left[\mathrm{Zn}(\mathrm{hkt})_{2}\right]$-treated group showed a significantly decreased BGL compared to the CNT group at the end of the treatment period (Table II). The BUN levels of the pioglitazone- and $\left[\mathrm{Zn}(\mathrm{hkt})_{2}\right]$-treated groups significantly decreased $(p<0.01)$. Furthermore, the GPT/ALT and GOT/AST levels in the pioglitazone-treated group increased significantly $(p<0.01$, Table III).

Liver morphology. After administering pioglitazone or $\left[\mathrm{Zn}(\mathrm{hkt})_{2}\right]$ for 4 months, the mouse livers and kidneys were collected and weighed. The weights of both the livers and kidneys of the mice in the various groups were not significantly different (Table III).

The histopathological changes induced by 4-month ingestion of HFD or the HFD containing pioglitazone or $\left[\mathrm{Zn}(\mathrm{hkt})_{2}\right]$ are summarised in Table IV, and the histopathological observations are shown in Figure 1. The livers of the CNT and the pioglitazone-treated group showed hepatocellular fatty changes after a 4-month ingestion of HFD. Fatty changes were mainly observed in the centrilobular area in the CNT and the pioglitazone-treated groups. However, although the $\left[\mathrm{Zn}(\mathrm{hkt})_{2}\right]$-treated group consumed the HFD, they showed a reduction in the level of fatty change.

Kidney morphology. Fatty changes were observed in the proximal tubular epithelia of the CNT group while [ $\left.\mathrm{Zn}(\mathrm{hkt})_{2}\right]$ treatment reduced the tubular fatty changes (Table IV). The histopathological observations are shown in Figure 2.

Organ distribution of $\mathrm{Zn}$. The $\mathrm{Zn}$ accumulation in the livers and kidneys of the C57BL/6J mice was determined after the treatment period using ICP-MS. The pioglitazone group showed slight decreases in both the hepatic and renal $\mathrm{Zn}$ concentration compared with the CNT group. In contrast, the hepatic and renal $\mathrm{Zn}$ concentrations of the $\left[\mathrm{Zn}(\mathrm{hkt})_{2}\right]$ group increased compared with those of the CNT group (Table V).
Table V. Organ distribution of $\mathrm{Zn}(\mu \mathrm{g} / \mathrm{g}$ of dry weight) in $\mathrm{C} 57 \mathrm{BL} / 6 \mathrm{~J}$ mice treated with high-fat diet (HFD, control, CNT), HFD and pioglitazone, or HFD and bis(hinokitiolato)Zn complex ([Zn(hkt) $\left.\left.{ }_{2}\right]\right)$.

\begin{tabular}{llll}
\hline Organs & CNT & Pioglitazone & {$\left[\right.$ Zn $\left.(\text { hkt })_{2}\right]$} \\
\hline Liver & $62.3 \pm 14.1$ & $54.2 \pm 10.9$ & $80.4 \pm 13.8^{*}$ \\
Kidney & $66.8 \pm 3.8$ & $63.6 \pm 2.6$ & $75.8 \pm 9.0^{*}$ \\
\hline
\end{tabular}

$* p<0.05$ vs. CNT.

\section{Discussion}

In the present study, the effects of pioglitazone and [ $\left.\mathrm{Zn}(\mathrm{hkt})_{2}\right]$ on lipid accumulation as well as blood biochemical and histopathological changes related to hepatocellular and renal cellular damage were investigated in C57BL/6J mice. We hypothesised that an HFD was associated with lipid deposition in the liver and kidney and our quantitative data confirmed the morphometric changes in each organ. The centrilobular fat deposition was observed in the livers of the HFD-treated control C57BL/6J mice. The area of fat deposition in the livers of the pioglitazone-treated group was higher than that in the $\left[\mathrm{Zn}(\mathrm{hkt})_{2}\right]$-treated group. Weinstock et al. (28) reported that pioglitazone-treated diabetic mice showed hepatocyte enlargement and severe lipid degradation and our results were consistent with this observation. Moreover, $\left[\mathrm{Zn}(\mathrm{hkt})_{2}\right]$ ameliorated the hepatocellular fat deposition in this study. Excessive fat accumulation in the liver is a characteristic of patients with insulin resistance with either too much or too little subcutaneous fat (29). Obesity and insulin resistance are the most common symptoms of non-alcoholic fatty liver disease (30). In our study, [Zn(hkt) 2 ] treatment decreased the high plasma TCHO and TG levels induced by feeding the C57BL/6J mice the HFD. These 

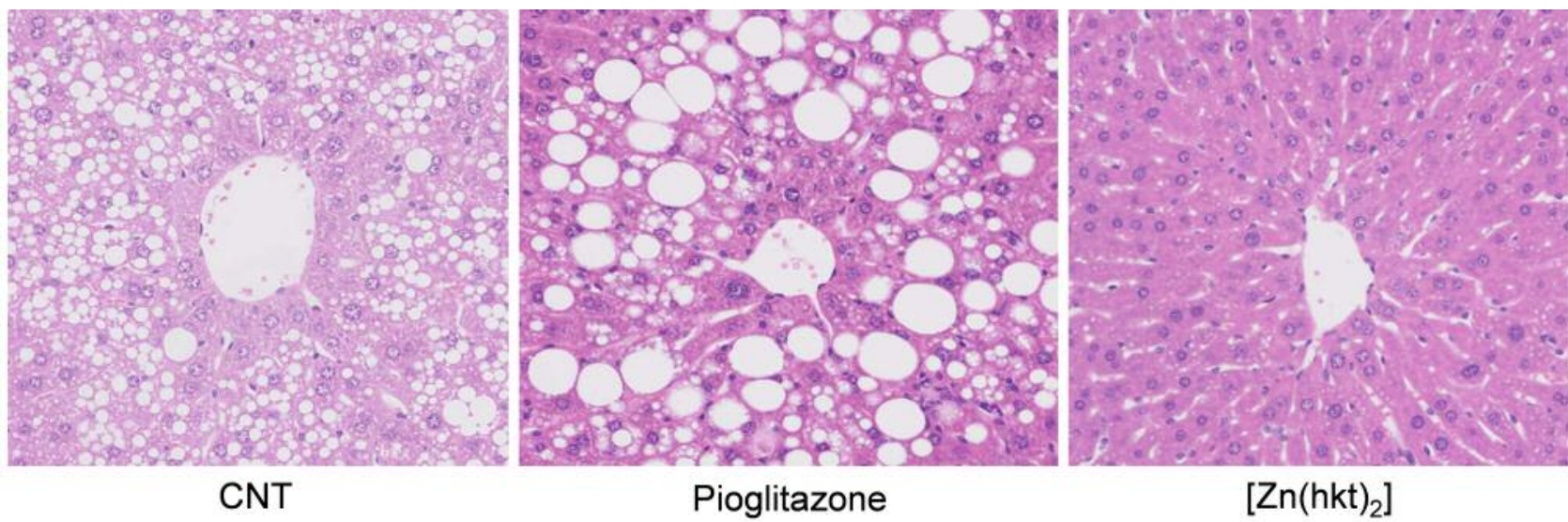

Figure 1. Histopathological changes in the livers of C57BL/6J mice; control (CNT), pioglitazone, and bis(hinokitiolato)Zn complex ([Zn(hkt) 2$])$. After a 4-month intake, CNT showed centrilobular fatty change.

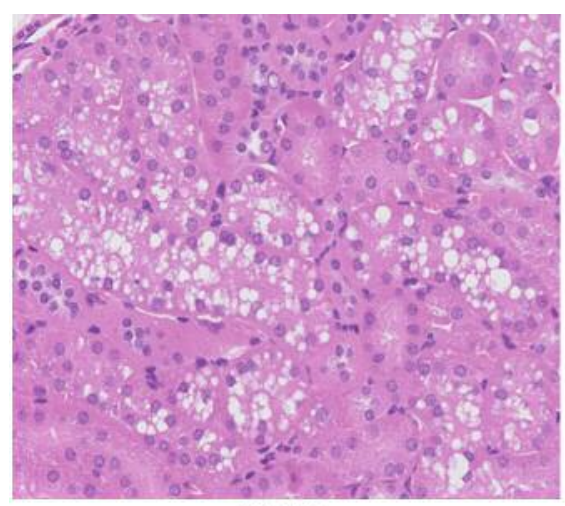

CNT

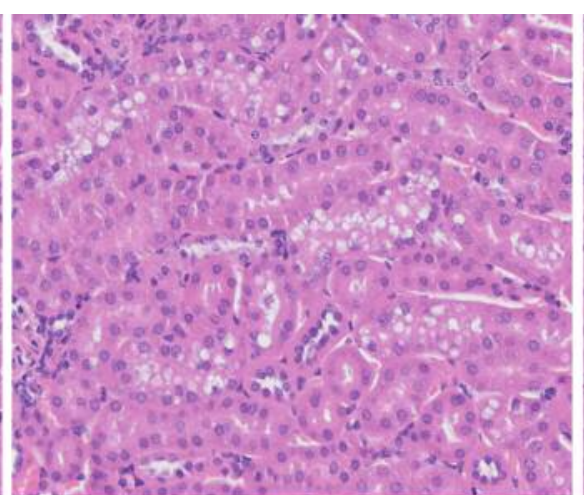

Pioglitazone

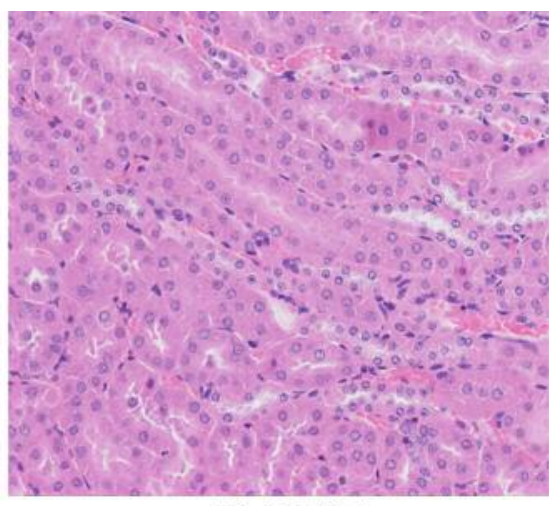

[Zn(hkt) $\left.)_{2}\right]$

Figure 2. Histopathological changes in the kidneys of C57BL/6J mice; control (CNT), pioglitazone, and bis(hinokitiolato)Zn complex ([Zn(hkt) 2$]$ ).

results suggest that the untreated $\mathrm{C} 57 \mathrm{BL} / 6 \mathrm{~J}$ mice developed hypertriglyceridaemia and hypercholesterolaemia as well as fatty liver disease. These blood biochemical parameters were consistent with the fat deposition in the liver. Furthermore, when the mice were fed the $\left[\mathrm{Zn}(\mathrm{hkt})_{2}\right]$, the $\mathrm{Zn}$ concentration of the liver increased compared with the untreated mice. These data suggest that $\mathrm{Zn}$ activated lipid metabolism such as beta-oxidation by activating or inhibiting some enzymes. It is well known that lipid accumulation in the liver is inhibited when 1) inflammation is reduced or 2) lipid absorption from food is regulated. Adiponectin is an adipocytokine with anti-inflammatory effects. Moreover, adiponectin activates beta-oxidation by activating AMPactivated protein kinase (AMPK). Yamane et al. (22) reported that $\left[\mathrm{Zn}(\mathrm{hkt})_{2}\right]$ induced the expression levels of adiponectin in $\mathrm{KK}-\mathrm{A}^{\mathrm{y}}$ mice. $\mathrm{Zn}$ also has anti-inflammatory effects throughout the body and, thus, in this study, the [ $\left.\mathrm{Zn}(\mathrm{hkt})_{2}\right]$ group showed less lipid accumulation in the liver.

Diabetic nephropathy often occurs during the progression of type 2 diabetes. Diabetic nephropathy is pathologically characterised by glomerular hypertrophy and hyperfiltration, thickening of the basement membrane, and accumulation of the extracellular matrix $(31,32)$. Numerous studies have reported that HFD induced metabolic syndrome or DM. Renal alterations such as lipid accumulation lead to increased organ weight and inflammatory infiltrates. The increased release of proinflammatory cytokines may be associated with kidney damage and oxidative stress (33-35). Moreover, numerous studies of renal function in DM and diabetic nephropathy evaluated the size of the glomerulus to determine the glomerular hypertrophy or collagen IV deposition as a measure of matrix deposition (36). 
Thus, in this study, we evaluated renal function by observing H\&E-stained histological sections and found that the CNT group showed increased lipid deposition while both the pioglitazone- and $\left[\mathrm{Zn}(\mathrm{hkt})_{2}\right]$-treated groups showed a reduction. Hirasawa et al. (37) reported that pioglitazone inhibited the mRNA expression of the receptor for advanced glycation end-products (RAGE) and transforming growth factor (TGF)- $\beta$. Thus, they concluded that pioglitazone improves obesity type diabetic nephropathy (37). The results of our study suggest that $\left[\mathrm{Zn}(\mathrm{hkt})_{2}\right]$ may have direct effects on the kidney similar to pioglitazone.

In conclusion, we evaluated the ectopic fat accumulation induced by an HFD using normal C57BL/6J mice. We found that pioglitazone and $\left[\mathrm{Zn}(\mathrm{hkt})_{2}\right]$ treatments both reduced the liver and kidney lipid accumulation, which ameliorated the lipid toxicity. [ $\left.\mathrm{Zn}(\mathrm{hkt})_{2}\right]$ has the potential to protect hepatic and renal function from the lipid toxicity, and its effects are likely higher than those of pioglitazone. This study suggests that $\left[\mathrm{Zn}(\mathrm{hkt})_{2}\right]$ could be a novel compound for the treatment of dyslipidaemia.

\section{Acknowledgements}

The Authors would like to thank Editage (www.editage.jp) for the English language editing.

\section{References}

1 Bjørnshave A and Hermansen K: Effects of dairy protein and fat on the metabolic syndrome and type 2 diabetes. Rev Diabet Stud 11: 153-166, 2014.

2 Nikolopoulou A and Kadoglou NP: Obesity and metabolic syndrome as related to cardiovascular disease. Expert Rev Cardiovasc Ther 10: 933-939, 2012.

3 Lee HS, Lee YJ, Chung YH, Nam Y, Kim ST, Park ES, Hong SM, Yang YK, Kim HC and Jeong JH: Beneficial effects of red yeast rice on high-fat diet-induced obesity, hyperlipidemia, and fatty liver in mice. J Med Food 18: 1095-1102, 2015.

4 Saravanan S and Pari L: Role of thymol on hyperglycemia and hyperlipidemia in high-fat diet-induced type 2 diabetic C57BL/6J mice. Eur J Pharmacol 761: 279-287, 2015.

5 Gomes MB and Negrato CA: Alpha-lipoic acid as a pleiotropic compound with potential therapeutic use in diabetes and other chronic diseases. Diabetol Metab Syndr 6: 80, 2014.

6 Jain SK, Croad JL, Velusamy T, Rains JL, and Bull R: Chromium dinicocysteinate supplementation can lower blood glucose, CRP, MCP-1, ICAM-1, creatinine, apparently mediated by elevated blood vitamin $\mathrm{C}$ and adiponectin and inhibition of NFkappaB, Akt, and Glut-2 in livers of zucker diabetic fatty rats. Mol Nutr Food Res 54: 1371-1380, 2010.

7 Zoja C, Corna D, Nava V, Locatelli M, Abbate M, Gaspari F, Carrara F, Sangalli F, Remuzzi G and Benigni A: Analogs of bardoxolone methyl worsen diabetic nephropathy in rats with additional adverse effects. Am J Physiol Renal Physiol 304: F808-819, 2013.
8 Yokoyama M, Tanigawa K, Murata T, Kobayashi Y, Tada E, Suzuki I, Nakabou Y, Kuwahata M and Kido Y: Dietary polyunsaturated fatty acids slow the progression of diabetic nephropathy in streptozotocin-induced diabetic rats. Nutr Res 30: 217-225, 2010.

9 DeFronzo RA and Abdul-Ghani M: Type 2 diabetes can be prevented with early pharmacological intervention. Diabetes Care 34(Suppl 2): S202-209, 2011.

10 DeFronzo RA, Tripathy D, Schwenke DC, Banerji M, Bray GA, Buchanan TA, Clement SC, Henry RR, Hodis HN, Kitabchi AE, Mack WJ, Mudaliar S, Ratner RE, Williams K, Stentz FB, Musi N and Reaven PD: Pioglitazone for diabetes prevention in impaired glucose tolerance. N Engl J Med 364: 1104-1115, 2011.

11 Kadowaki S, Munekane M, Kitamura Y, Hiromura M, Kamino S, Yoshikawa Y, Saji H and Enomoto S: Development of new zinc dithiosemicarbazone complex for use as oral antidiabetic agent. Biol Trace Elem Res 154: 111-119, 2013.

12 Yoshikawa $\mathrm{Y}$ and Yasui H: Zinc complexes developed as metallopharmaceutics for treating diabetes mellitus based on the bio-medicinal inorganic chemistry. Curr Top Med Chem 12: 210-218, 2012.

13 Yoshikawa Y, Murayama A, Adachi Y, Sakurai H, and Yasui H: Challenge of studies on the development of new $\mathrm{Zn}$ complexes $\left(\mathrm{Zn}(\mathrm{opt})_{2}\right)$ to treat diabetes mellitus. Metallomics 3: 686-692, 2011.

14 Naito Y, Yoshikawa Y, Masuda $\mathrm{K}$ and Yasui $\mathrm{H}$ : Bis(hinokitiolato)zinc complex $\left(\left[\mathrm{Zn}(\mathrm{hkt})_{2}\right]\right)$ activates Akt/protein kinase B independent of insulin signal transduction. J Biol Inorg Chem 21: 537-548, 2016.

15 Bellomo E, Birla Singh K, Massarotti A, Hogstrand C and Maret $\mathrm{W}$ : The metal face of protein tyrosine phosphatase 1B. Coord Chem Rev 327-328: 70-83, 2016.

16 Plum LM, Brieger A, Engelhardt G, Hebel S, Nessel A, Arlt M, Kaltenberg J, Schwaneberg U, Huber M, Rink L, and Haase $\mathrm{H}$ : PTEN-inhibition by zinc ions augments interleukin-2mediated Akt phosphorylation. Metallomics 6: 1277-1287, 2014.

17 Yoshikawa Y, Hirata R, Yasui H and Sakurai H: Alphaglucosidase inhibitory effect of anti-diabetic metal ions and their complexes. Biochimie 91: 1339-1341, 2009.

18 Ezaki O: IIb group metal ions $\left(\mathrm{Zn}^{2+}, \mathrm{Cd}^{2+}, \mathrm{Hg}^{2+}\right)$ stimulate glucose transport activity by post-insulin receptor kinase mechanism in rat adipocytes. J Biol Chem 264: 16118-16122, 1989.

19 Tappy L, Lê KA, Tran C and Paquot N: Fructose and metabolic diseases: new findings, new questions. Nutrition 26: 1044-1049, 2010.

20 Di Luccia B, Crescenzo R, Mazzoli A, Cigliano L, Venditti P, Walser JC, Widmer A, Baccigalupi L, Ricca E and Iossa S: Rescue of fructose-induced metabolic syndrome by antibiotics or faecal transplantation in a rat model of obesity. PLoS One 10: e0134893, 2015.

21 Moroki T, Yoshikawa Y, Yoshizawa K, Tsubura A and Yasui H: Morphological analysis of the pancreas and liver in diabetic KK$\mathrm{A}^{\mathrm{y}}$ mice treated with zinc and oxovanadium complexes. Metallomics 6: 1632-1638, 2014.

22 Yamane M, Adachi Y, Yoshikawa Y and Sakurai H: A new antidiabetic $\mathrm{Zn}(\mathrm{II})-$ hinokitiol ( $\beta$-Thujaplicin) complex with $\mathrm{Zn}\left(\mathrm{O}_{4}\right)$ coordination mode. Chem Lett 34: 1694-1695, 2005. 
23 Ishida H, Takizawa M, Ozawa S, Nakamichi Y, Yamaguchi S, Katsuta H, Tanaka T, Maruyama M, Katahira H, Yoshimoto K, Itagaki $\mathrm{E}$ and Nagamatsu S: Pioglitazone improves insulin secretory capacity and prevents the loss of $\beta$-cell mass in obese diabetic $\mathrm{db} / \mathrm{db}$ mice: possible protection of $\beta$ cells from oxidative stress. Metabolism 53: 488-494, 2004.

24 Kubota N, Terauchi Y, Kubota T, Kumagai H, Itoh S, Satoh H, Yano W, Ogata H, Tokuyama K, Takamoto I, Mineyama T, Ishikawa M, Moroi M, Sugi K, Yamauchi T, Ueki K, Tobe K, Noda T, Nagai R and Kadowaki T: Pioglitazone ameliorates insulin resistance and diabetes by both adiponectin-dependent and -independent pathways. J Biol Chem 281: 8748-8755, 2006.

25 Hirukawa H, Kaneto H, Shimoda M, Kimura T, Okauchi S, Obata A, Kohara K, Hamamoto S, Tawaramoto K, Hashiramoto $\mathrm{M}$ and Kaku K: Combination of DPP-4 inhibitor and PPAR $\gamma$ agonist exerts protective effects on pancreatic $\beta$-cells in diabetic $\mathrm{db} / \mathrm{db}$ mice through the augmentation of IRS-2 expression. Mol Cell Endocrinol 413: 49-60, 2015.

26 Adachi Y, Yoshida J, Kodera Y, Kiss T, Jakusch T, Enyedy EA, Yoshikawa $\mathrm{Y}$ and Sakurai $\mathrm{H}$ : Oral administration of a zinc complex improves type 2 diabetes and metabolic syndromes. Biochem Biophys Res Commun 351: 165-170, 2006.

27 Yoshikawa Y, Adachi Y and Sakurai H: A new type of orally active anti-diabetic $\mathrm{Zn}(\mathrm{II})$-dithiocarbamate complex. Life Sci 80: 759-766, 2007.

28 Weinstock RS, Murray FT, Diani A, Sangani GA, Wachowski MB and Messina JL: Pioglitazone: in vitro effects on rat hepatoma cells and in vivo liver hypertrophy in KKAy mice. Pharmacology 54: 169-178, 1997.

29 Yki-Jarvinen H and Westerbacka J: The fatty liver and insulin resistance. Curr Mol Med 5: 287-295, 2005.

30 Neuschwander-Tetri BA and Caldwell SH: Nonalcoholic steatohepatitis: Summary of an AASLD Single Topic Conference. Hepatology 37: 1202-1219, 2003.
31 Kanwar YS, Wada J, Sun L, Xie P, Wallner EI, Chen S, Chugh $S$ and Danesh FR: Diabetic nephropathy: mechanisms of renal disease progression. Exp Biol Med (Maywood) 233: 4-11, 2008.

32 Zelmanovitz T, Gerchman F, Balthazar AP, Thomazelli FC, Matos JD and Canani LH: Diabetic nephropathy. Diabetol Metab Syndr 1: 10, 2009.

33 Sasson AN and Cherney DZ: Renal hyperfiltration related to diabetes mellitus and obesity in human disease. World J Diabetes 3: 1-6, 2012.

34 Cherney DZ, Scholey JW and Miller JA: Insights into the regulation of renal hemodynamic function in diabetic mellitus. Curr Diabetes Rev 4: 280-290, 2008.

35 de Castro UG, dos Santos RA, Silva ME, de Lima WG, Campagnole-Santos MJ and Alzamora AC: Age-dependent effect of high-fructose and high-fat diets on lipid metabolism and lipid accumulation in liver and kidney of rats. Lipids Health Dis 12: 136, 2013.

36 Wei P, Lane PH, Lane JT, Padanilam BJ and Sansom SC: Glomerular structural and functional changes in a high-fat diet mouse model of early-stage Type 2 diabetes. Diabetologia 47: 1541-1549, 2004.

37 Hirasawa Y, Matsui Y, Yamane K, Yabuki SY, Kawasaki Y, Toyoshi T, Kyuki K, Ito M, Sakai $\mathrm{T}$ and Nagamatsu T: Pioglitazone improves obesity type diabetic nephropathy: relation to the mitigation of renal oxidative reaction. Exp Anim 57: 423-432, 2008.
Received September 12, 2017

Revised September 28, 2017

Accepted September 29, 2017 